JURNAL PENDIDIKAN, p-ISSN 2715-095X, e-ISSN 2686-5041

Volume 29, No.2, Juli 2020 (101-108)

Online: http://journal. univetbantara. ac. id/index.php/jp

\title{
Pendidikan Segregasi, Mainstreaming, Integrasi dan Inklusi, Apa Bedanya?
}

\section{Ibdaul Latifah}

\author{
Institut Agama Islam Negeri Salatiga, Email: latifahibdaul@,gmail.com
}

\begin{abstract}
Abstrak: Penelitian ini bertujuan menjelaskan tentang perbedaan istilah pendidikan segregasi, mainstreaming, integrasi dan inklusi. Metode penelitian yang digunakan adalah studi kepustakaan dengan metode dokumentasi sebagai emtode pengumpulan data.Teknik analisis datanya menggunakan analisis isi. Hasil penelitian ini adalah adanya perbedaan istilah dalam pendidikan segregasi, mainstreaming, integrasi dan inklusi. Perbedaannya terletak pada jenis layanan, pendidikan segregasi layanan pendidikan yang memisahkan anak berkebutuhan khusus dengan anak normal, pendidikan mainstreaming, integrasi dan inklusi menggabungkan layanan pendidikan anak berkebutuhan khusus dengan anak normal pada sekolah reguler. Mainstreaming adalah model layanan pendidikan yang didalamnya terdapat konsep integrasi dimana peserta didik menyesuaikan dengan kegiatan yang ada disekolah sedangkan inklusi layanan pendidikan anak berkebutuhan khusus dengan konsep sekolah yang menyesuaikan dengan kebutuhan peserta didik.
\end{abstract}

Kata-kata Kunci: segregasi, mainstreaming, integrasi, inklusi.

\section{Segregation Education, Mainstreaming, Integration And Inclusion, What's The Difference?}

\author{
Ibdaul Latifah \\ Institut Agama Islam Negeri Salatiga, Email: latifahibdaul@gmail.com
}

\begin{abstract}
This research aims to explain the different terms of segregation, mainstreaming, integration and inclusion education. The research method used is the study of literature with the method of documentation as a method of data collection. The data analysis technique uses content analysis. The results of this study are the different terms in segregation, mainstreaming, integration and inclusion education. The difference lies in the type of service, education segregation of education services that separates children with special needs from normal children, mainstreaming education, integration and inclusion combining education services of children with special needs with normal children in regular schools. Mainstreaming is an educational service model in which there is a concept of integration in which students adjust to existing activities at school while the inclusion of educational services for children with special needs with the concept of schools that adjust to the needs of students.
\end{abstract}

Keywords: segregation, mainstreaming, integration, inclusion. 


\section{Pendahuluan}

Pendidikan merupakan kebutuhan pokok manusia yang sangat penting karena di dalam pendidikan terdapat transfer knowledge dari generasi ke generasi dalam bentuk pengajaran maupun pelatihan. Namun bukan berarti pendidikan harus dibimbing oleh orang lain pendidikan juga dapat dilakukan secara mandiri. Menurut UU No. 20 Tahun 2003 tentang SISDIKNAS pendidikan adalah usaha sadar dan terencana untuk mewujudkan suasana belajar dan proses pembelajaran agar peserta didik secara aktif mengembangkan potensi dirinya untuk memiliki kekuatan spiritual keagamaan, pengendalian diri, kepribadian, kecerdasan, akhlak mulia serta keterampilan yang diperlukan dirinya masyarakat, bangsa dan Negara. Pendidikan tidak hanya untuk sebagian orang tetapi pendidikan untuk semuanya. Semua warga Negara mempunyai hak mendapatkan pendidikan tidak memandang suku, agama golongan dan lain sebagainya. Sesuai dengan UU N0. 20 tahun 2003 pasal 5 ayat 1 yang menyatakan bahwa setiap warga Negara mempunyai hak yang sama untuk memperoleh pendidikan yang bermutu begitu juga dengan anak berkebutuhan khusus.

Anak berkebutuhan khusus adalah anak yang memerlukan penangan khusus karena adanya gangguan perkembangan dan kelainan yang dialaminya (Desiningrum, 2016). Kementerian Pemberdayaan Perempuan dan Perlindungan Anak Republik Indonesia 2013, menjelaskan bahwa anak berkebutuhan khusus adalah " anak yang mengalami keterbatasan atau keluarbiasaan baik fisik, mental-intelektual, sosial, maupun emosional yang berpengaruh secara signifikan dalam proses pertumbuhan atau perkembangannya dibandingkan dengan anak-anak lain yang seusia dengannya". Secara umum dapat disimpulkan bahwa anak berkebutuhan khusus adalah anak yang berbeda dengan anak normal pada umumnya yang mengalami keterbatasan dari segi fisik, mental, sosial maupun intelektual bahkan terkadang juga mengalami keluarbiasaan dari anak normal pada umumnya. Dalam bidang pendidikan Anak berkebutuhan khusus mempunyai hak yang sama dengan anak lainnya. Meskipun layanan pendidikan yang diperuntukkan bagi anak berkebutuhan khusus tidak sama dengan anak normal karena mereka memiliki keunikan dan karakteristik tersendiri. Keadaan inilah yang menuntut untuk memberikan layananan pendidikan yang sesuai dengan yang dibutuhkan anak berkebutuhan khusus.

Di Indonesia sudah banyak sekolah-sekolah yang menyediakan layanan khusus bagi anak berkebutuhan khusus, ada pendidikan segregasi yang sudah berlangsung selama satu abad lebih, sejak dimulainya pendidikan anak tunanetra pada tahun 1901 di Bandung (Baharun, Hasan, 2018). Pada tahun 1986 setelah dilakukan uji coba di beberapa sekolah umum di kota besar untuk menerima anak ABK maka disusunlah buku petunjuk Teknis Pendidikan Integrasi di Sekolah dasar yang kemudian disusul oleh SK Mendikbud nomo2 022/U/1986 tentang pendidikan integrasi bagi Anak Cacat. Konsep pendidikan integrasi ini muncul setelah adanya konsep mainstreaming sebagai penyedia pendidikan khusus bagi anak berkebutuhan khusus yang ada di sekolah atau kelas umum. Kemudian seiring berkembangnya zaman ada pendidikan inklusif yang berkembang di Indonesia pada awal tahun 2000 kemudian disusul dengan penyelenggaraan Konvensi Nasional sehingga menghasilkan Deklarasi Bandung pada tahun 2004 untuk berkomitmen menuju pendidikan inklusif. Terdapat beberapa istilah ataupun konsep layanan bagi anak berkebutuhan khusus, dari pendidikan segresi, mainstreaming, integrasi dan juga pendidikan inklusif. Dari beberapa konsep ini membuat bingung sebagian orang tentang konsep-konsep layanan anak 
berkebutuhan khusus. Dari permasalahan diatas maka penulis ingin membedah konsepkonsep layanan anak berkebutuhan khusus dari pendidikan segresi, mainstreaming, integrasi dan inklusi apa bedanya?

\section{Metode Penelitian}

Dalam penelitian ini menggunakan metode studi kepustakaan (library research). Penelitian kepustakaan adalah teknik pengumpulan data dengan mengadakan studi penelaahan terhadap buku-buku, literature-literatur, catatan-catatan dan laporan-laporan yang ada hubungannya dengan masalah yang dipecahkan (Nazir, 2003). Metode pengumpulan data yang digunakan adalah metode dokumentasi. Jenis datanya menggunakan data sekunder. Sedangkan analisis isi digunakan untuk menganalisis data. Data yang diperoleh dikompilasi, dianalisis dan disimpulkan supaya mendapatkan kesimpulan mengenai studi literature.

\section{Pembahasan}

Segregasi secara etimologis berasal dari kata segregate yang mempunyai arti (memisahkan, memencilkan) atau segregation (diartikan Pemisahan). Para ilmuwan mengartikan segregasi sebagai proses pemisahan suatu golongan dari golongan lainnya atau pengasilan atau juga pengucilan. Sedangkan pendidikan segregasi yang berkaitan dengan pendidikan luar biasa adalah suatu sistem pendidikan bagi anak berkebutuhan khusus yang terpisah dari sistem layanan pendidikan anak normal (Casmini, 2007). Pendidikan segregasi adalah sistem layanan pendidikan bagi anak berkebutuhan khusus tertua yang ada di tanah air kita. Pendidikan segregasi bukan hanya sekedar pemisahan tempat atau lokasi tetapi juga keseluruhan program penyelenggaraan yang terpisah antara anak berkebutuhan khusus dengan anak normal. Pendidikan segregasi muncul akibat anggapan bahwa anak berkebutuhan khusus tidak sama dengan anak-anak normal pada umumnya. Artinya terdapat perbedaan sehingga timbul kekhawatiran terhadap kemampuan anak-anak berkebutuhan khusus apabila disatukan dengan anak-anak normal pada umumnya. Dengan anggapan ini anak berkebutuhan khusus haruslah mendapatkan layanan pendidikan secara khusus (terpisah dari anak normal). Maka munculah konsep pendidikan Luar Biasa identik dengan Sekolah Luar Biasa (SLB).

Seiring disahkanya Undang-undang Pendidikan Nasional (UUSPN) No.2 Tahun 1989 yang diatur dengan Peraturan Pemerintah No. 72 tahun 1991, maka bentuk pendidikan segregasi menyesuaikan diri dengan terdapat dua cara untuk mendirikan sekolah yaitu Sekolah Luar Biasa (SLB) dan Sekolah Dasar Luar Biasa (SDLB). Namun seiring berjalannya waktu terdapat 4 bentuk penyelenggaraan pendidikan dengan sistem segregasi yaitu: a) Sekolah Luar Biasa, b) Sekolah Luar Biasa Berasrama, c) Kelas Jauh /Kelas Kunjungan dan d) Sekolah Dasar Luar Biasa. Sekolah Luar Biasa adalah sebuah lembaga pendidikan formal yang melayani pendidikan bagi anak-anak berkebutuhan khusus (Pramartha, 2015). Dalam Pelaksanaanya SLB Terbagi beberapa jenis : (a). SLB Bagian A untuk anak berkebutuhan khusus yang menyandang kelainan pada penglihatan (Tunanetra). (b). SLB Bagian B untuk anak berkebutuhan khusus yang menyandang kelainan pada pendengaran (Tunarungu). (c). SLB Bagian C untuk anak berkebutuhan khusus Tunagrahita 
ringan sedangkan SLB Bagian C1 untuk anak berkebutuhan khusus Tunagrahita sedang. (d). SLB Bagian A untuk anak berkebutuhan khusus untuk Tunadaksa tanpa adanya gangguan kecerdasan sedangkan SLB D1 untuk anak berkebutuhan khusus Tunadaksa dengan gangguan kecerdasan. (e). SLB Bagian E yaitu lembaga pendidikan yang memberikan pelayanan pendidikan secara khusus untuk peserta didik tunalaras. (f). SLB Bagian G yaitu lembaga pendidikan yang memberikan layana untuk peserta didik tunaganda.

Sekolah Luar Biasa Berasrama adalah bentuk sekolah luar biasa yang didalamnya terdapat fasilitas asrama. Anak berkebutuhan khusus yang sekolah di SLB berasrama tinggal diasrama. Asrama dan sekolah menjadi satu pengelolaan sehingga didalamnya terdapat tingkatan persispan, dasar dan tingkat lanjut juga terdapat unit asrama. Pemerintah menyediakan Kelas kunjung atau kelas jauh untuk melayani pendidikan anak berkebutuhan khusus yang bertempat tinggal jauh dari SLB atau SDLB. Tenaga pengajar yang bertugas berasal dari guru SLB-SDLB terdekatnya. Mereka menjadi guru kunjung sedangkan kegiatan administrasinya dilaksanakan di SLB terdekat. Sekolah Dasar Luar Biasa adalah sekolah pada tingkat dasar yang menampung beberapa jenis kelainan, yaitu : tunanetra, tunarungu, tunagrahita, tunadaksa, bahkan juga tunaganda yang ditampung dalam satu atap (Casmini, 2007). Terdapat beberapa kelas-kelas sebagai pemisah untuk menyesuaikan jenis kelainannya. SDLB didirikan dengan tujuan menuntaskan wajib belajar pada tingkat sekolah dasar.

Menurut Irvine Mainstreaming didefinisikan sebagai integrasi sosial, instruksional dan temporal anak berkebutuhan khusus dengan teman-teman normal/biasa, berdasarkan kepada kebutuhan pendidikan yang diukur secara individual, memerlukan klasifikasi tanggungjawab koordinasi dalam penyusunan program oleh team dari berbagai profesi dan disiplin ilmu (Mambela, 2010). Istilah Mainstreaming sering digunakan dalam kaitannya dengan isu-isu lain seperti gender dan hak anak di dalam kebijakan pembangunan secara umum. Dalam hal ini, mainstreaming dapat diartikan sebagai suatu proses politik untuk membawa suatu isu dari tepi ke tengah (mainstream), agar diterima oleh mayoritas. Ini dapat diartikan sebagai upaya agar isu masuk ke dalam agenda, dan mengubah kesadaran orang dari memandangnya sebagai hal kecil menjadi permasalahan inti dalam suatu perdebatan(Stubbs, 2008).

Mainstreaming memberikan kesempatan kepada anak berkebutuhan khusus untuk ditempatkan secara bersama ke dalam kelas regular (umum) dengan teman sebayanya dan belajar bersama dengan kemampuan yang dimilikinya dengan beberapa modifikasi dari sekolah dari segi layanan dan pengaturan pendidikan (Lópe, 2016). Dengan kata lain mainstreaming adalah layanan pendidikan khusus yang ditujukan kepada anak berkebutuhan khusus dengan menempatkan mereka ke dalam sekolah-sekolah yang umum dengan berbagai modifikasi layanan dan pengaturan dari sekolah dalam melayani anak berkebutuhan khusus. Konsep Mainstreaming adalah bahwa pendidikan khusus tidak harus terpisah dari yang umum. Dari beberapa pengertian mainstreaming menunjukkan bahwa pendidikan anak berkebutuhan khusus bersifat tidak tetap (dapat berubah sesuai dengan kebutuhan), berdasarkan dari hasil kebutuhan pendidikan yang banyak melibatkan berbagai profesi seperti psikolog, tenaga medis, guru khusus, psikiater, dan fisioterapi 
Integrasi adalah istilah yang banyak digunakan oleh kalangan masyarakat yang berarti memasukkan anak berkebutuhan khsuus ke dalam sekolah regular. Integrasi sering juga disebut dengan mainstreaming(Stubbs, 2008). Akan tetapi pendidikan integrasi belum tentu juga menerapkan konsep mainstreaming. Contoh kasusnya adalah beberapa anak sekolah dasar yang tanpa disadari adalah anak berkebutuhan khusus dan tampaknya memang pendidikan integrasi karena antara yang berkebutuhan khusus dan anak normal menjadi satu kelas, tetapi pengajarannya terkadang tidak menerapkan konsep mainstreaming(Mambela, 2010). Sistem pendidikan integrasi juga disebut dengan sistem pendidikan terpadu yaitu sistem pendidikan yang memadukan anak berkebutuhan khusus dengan anak normal. Penyatuan tersebut dapat bersifat sebagian atau keterpaduan dalam rangka sosialisasi bahkan dapat bersifat menyeluruh.

Ada tiga bentuk keterpaduan dalam layanan pendidikan bagi anak berkebutuhan khusus menurut Depdiknas (1986). Ketiga bentuk tersebut adalah : (a). Bentuk Kelas Biasa

Dalam kelas ini anak berkebutuhan khusus belajar secara penuh dengan menggunakan kurikulum biasa. Maka dari itu, diharapkan adanya pelayanan dan bantuan dari guru kelas atau guru bidang studi dalam melaksanakan kegiatan belajar. Cara mengajar dan penilaian yang digunakan tidak sama dengan kelas umum. Untuk mata pelajaran tertentu harus disesuaikan dengan kebutuhan anak berkebutuhan khusus misalnya menggambar, matematika, menulis perlu disesuaikan bagi anak tunanetra, jangan disamakan dengan anak normal. (b). Kelas Biasa dengan Ruang bimbingan khusus. Dikelas ini anak berkebutuhan khusus belajar di kelas biasa dengan menggunakan kurikulum biasa serta mengikuti layanan khusus untuk mata pelajaran tertentu yang tidak dapat diikuti oleh anak berkebutuhan khusus bersama anak normal. Pelayanan khusus diberikan oleh guru pembimbing khusus di ruang bimbingan khsuus. (c). Bentuk kelas khusus. Bentuk kelas khusus juga disebut dengan keterpaduan local atau bangunan atau keterpaduan yang bersifat sosialisasi. Pada kelas ini, guru pembimbing khusus berfungsi sebagai pelaksana program di kelas khusus. Pendekatan, metode, dan cara penilaian yang digunakan adalah yang sudah biasa digunakan pada sekolah luar biasa. Keterpaduan pada tingkat ini hanya bersifat fisik dan sosial, artinya anak berkebutuhan khusus dapat dipadukan untuk kegiatan yang bersifat non akademik, seperti olahraga, keterampilan, juga sosialisasi pada jam istirahat.

Pendidikan inklusi merupakan sebuah sistem penyelenggaraan pendidikan terbuka untuk anak berkebutuhan khusus bersama dengan anak pada umumnya dalam satu lingkungan pendidikan (Shofa, 2018). Menurut Bintoro yang dikutip oleh Abdul Rahim menjelaskan bahwa pendidikan inklusi adalah proses pendidikan yang memungkinkan semua anak berkesempatan untuk berpartisipasi secara penuh dalam kegiatan kelas regular, tanpa memandang kelainan, ras, atau karakteristik lainnya (Rahim, 2016). Menurut permendiknas RI No 70 tahun 2009 pasal 1 Pendidikan Inklusi didefinisikan sebagai sistem penyelenggaraan pendidikan yang memberikan kesempatan kepada semua peserta didik yang memiliki kelainan dan memilki potensi kecerdasan dan atau bakat istimewa untuk mengikuti pendidikan atau pembelajaran dalam satu lingkungan pendidikan secara bersama-sama dengan peserta didik pada umumnya. Dari beberapa pengertian di atas dapat diambil kesimpulan bahwa pendidikan inklusi adalah penggabungan pendidikan semua anak baik yang berkebutuhan khusus ataupun yang mempunyai kesulitan dalam hal lainnya 
disekolah regular (umum). Hal ini sesuai dengan pendapat Neil dalam Bhota menjelaskan bahwa inklusi pada dasarnya mencakup tantangan penyediaan lingkungan belajar terbaik untuk semua anak, tidak hanya dikhususkan untuk anak berkebutuhan khusus (penyandang cacat) tetapi juga anak yang mengalami kemiskinan, sakit atau hambatan lain dalam belajar (Botha \& Kourkoutas, 2016).

Untuk membedakan antara pendidikan segeresi, mainstreaming, integrasi dan inklusi perlu adanya sebuah ilustrasi.

\section{Ilustrasi 1}

Doni adalah anak tunanetra sehingga oleh keluarganya Doni disekolahkan di sekolah SLB bagian A yang dapat berkumpul dengan anak yang juga mengalami kelainan dalam penglihatan (tuna netra).

\section{Ilustrasi 2}

Anis adalah anak tunagrahita, tetapi Anis adalah anak yang cerdas sehingga oleh keluarganya disekolahkan disekolah umum. Disekolah tersebut Anis harus mengikuti segala kegiatan dan kurikulum yang sudah diatur oleh sekolah. Sekolah memfasilitasi guru pembimbing anak berkebutuhan khsuus dalam ruangan tersendiri.

\section{Ilustrasi 3}

Disuatu sekolah umum terdapat anak yang mengalami kesulitan dalam pembelajaran karena anak tersebut mengalami kelainan dalam pendengaraan. Anak tersebut harus mengikuti seluruh kegiatan sekolah tanpa dibedakan dengan anak normal yang berda disekolah tersebut.

\section{Ilustrasi 4}

Tini anak yang berkebutuhan khsuus karena mengalami kelainan dalam penglihatan, toni bersekolah disekolah umum, akan tetapi sekolah tersebut sangat memfasilitasi semua kebutuhan Tini dengan menyediakan guru pendamping, materi pelajaran dan fasilitas pendidikan disesuaikan dengan kondisi Tini.

Keempat ilustrasi tersebut terdapat persamaan dan perbedaan. Persamaanya adalah kesemua anak yang ada dalam ilustrasi berkebutuhan khusus baik yang mengalami kelainan dalam penglihatan, pendengaran maupun mengalami kesulitan dalam belajar. Terdapat 4 perbedaan dalam ilustrasi diatas. Ilustrasi pertama adalah yang disebut dengan pendidikan segresi, dimana anak berkebutuhan khusus disekolahkan disekolah khusus. Kemudian ilustrasi ke 2 menggambarkan konsep pendidikan mainstreaming dimana anak berkebutuhan khusus ikut sekolah di sekolah umum dan harus mengikuti segala bentuk kegiatan disekolah tersebut meskipun disediakan guru pembimbing khusus. Ilustrasi ke 3 menggambarkan pendidikan integrasi tetapi tidak menggunakan konsep mainstreaming karena kurikulum dan segala kegiatan tidak disesuaikan dengan anak berkebutuhan khusus. Pendidikan integrasi adalah bentuk layanan anak berkebutuhan khusus dengan menggunakan konsep mainstreaming. Sedangkan ilustrasi ke 4 adalah penggambaran tentang pendidikan konsep pendidikan inklusi dimana sekolah umum menyediakan segala 
bentuk fasilitas, mata pelajaran dan lain sebagainya sesuai dengan kebutuhan anak berkebutuhan khusus. Dari 4 konsep pendidikan diatas yang sangat berbeda adalah pendidikan segregasi dimana dalam konsep pendidikan ini anak berkebutuhan khusus mendapatkan layanan pendidikan di sekolah khusus dengan teman-teman sesamanya yang berkebutuhan khusus. Sedangkan untuk 3 jenis pendidikan mainstreaming, integrasi dan inklulsi adalah bentuk pelayanan pendidikan dengan cara menggabungkan anak berkebutuhan khusus ke dalam sekolah umum. Integrasi dan inklusi adalah 2 jenis pendidikan layanan khusus bagi anak berkebutuhan khusus dengan menerapkan model mainstreaming. Jadi mainstreaming adalah modelnya sedangkan integrasi dan inklusi adalah jenis dari model mainstreaming.

Untuk lebih jelasnya dapat dilihat pada gambar dibawah ini.

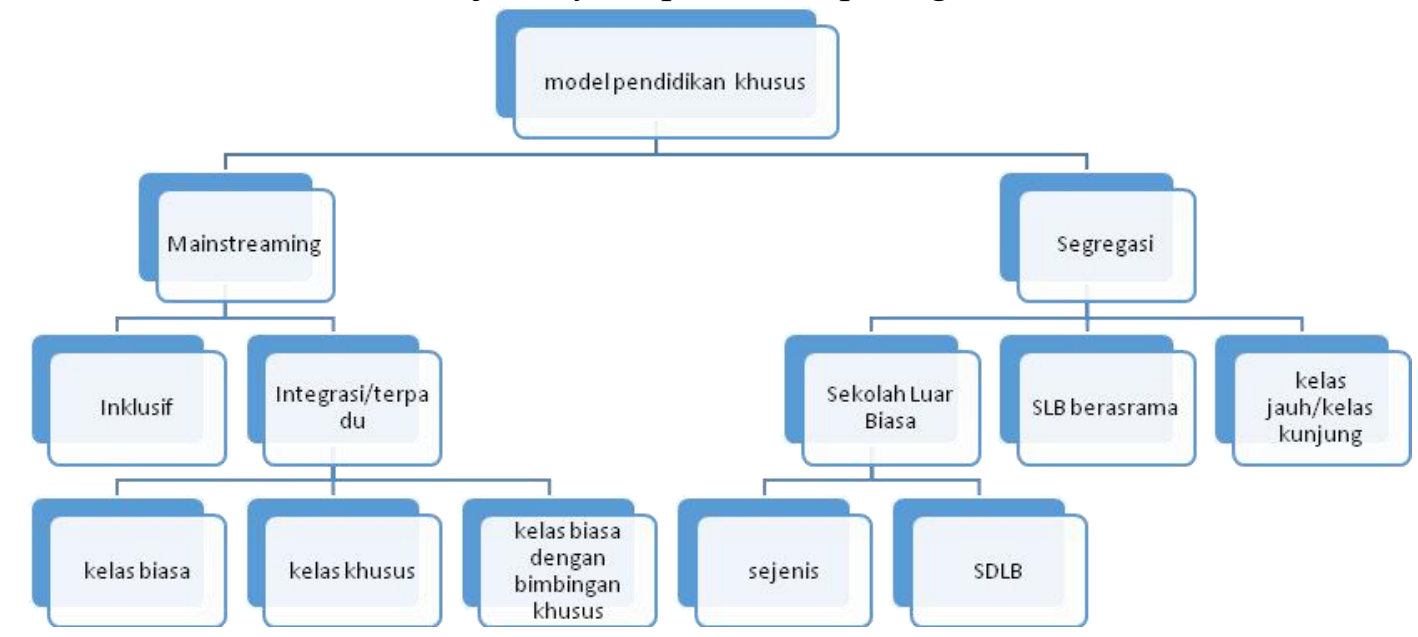

Gambar 1. Model Layana Pendidikan Khusus

Meskipun terdapat perbedaan dari beberapa istilah diatas namun kesemuanya mempunyai persamaan dalam konsep positif layanan pendidikan anak misalnya: (a). Semua anak, termasuk anak penyandang cacat berhak atas pendidikan. (b). Adanya komitmen untuk menemukan cara membantu anak yang belajar dengan cara dan kecepatan yang berbeda-beda agar benar-benar dapat belajar. (c). Mempromosikan perkembangan potensi individu anak secara holistic secara fisik, linguistic, social, kognitif sensor. (d). Mendukung bermacam-macam metode komunikasi untuk penyandang berbagai kecacatan (bahasa isyarat, braille, papan tanda, bicara dengan bantuan computer, Makaton, dll) (Stubbs, 2008)

\section{Simpulan dan saran}

Pendidikan segregasi, mainstreaming, integrasi dan inklusi adalah layanan pendidikan bagi anak berkebutuhan khusus. Pendidikan segregasi adalah layanan pendidikan yang memisahkan anak berkebutuhan khusus dengan anak normal dalam layanan dalam bidang pendidikan, sehingga anak berkebutuhan khusus berada disekolah khusus. Sedangkan pendidikan mainstreaming, intergrasi dan juga inklusi adalah layanan pendidikan yang menyatukan anak berkebutuhan khusus dengan anak normal dalam bidang pendidikan yang ditempatkan dalam satu sekolah umum. Meskipun sama tetapi mainstreaming, integrasi dan inklusi mempunyai perbedaan dalam segi pelayanan, jika mainstreaming dan integrasi 
peserta didik menyesuaikan segala kegiatan yang ada disekolah jika inklusi sekolah yang menyesuaikan kebutuhan peserta didik. Meskipun mainstreaming sering diistilahkan dengan integrasi akan tetapi istilah ini berbeda, mainstreaming adalah model layanan khusus yang didalamnya terdapat konsep integrasi. Berdasarkan kesimpulan di atas, maka peneliti menyampaikan saran kepada peneliti selanjutnya untuk lebih banyak mengkaji tentang penelitian pendidikan yang berhubungan dengan layanan anak berkebutuhan khusus.

\section{Daftar rujukan}

Baharun, Hasan, R. A. (2018). Berkebutuhan Khusus Dalam Perspektif. Program Studi PGMI, 5 Nomor 1(3), 60.

Botha, J., \& Kourkoutas, E. (2016). A community of practice as an inclusive model to support children with social, emotional and behavioural difficulties in school contexts. International Journal of Inclusive Education, 20(7), 784-799.

Casmini, M. (2007). Pendidikan segregasi. Bandung: Universitas Pendidikan Indonesia.

Desiningrum, D. R. (2016). Psikologi Anak Berkebutuhan Khusus. In Depdiknas (cetakan pe). Yogyakarta: Psikosain Ruko Jambusari 7A Yogyakarta.

Firdaus, E. (2010). Disampaikan dalam Seminar Nasional Pendidikan di Universitas Jenderal Soedirman (UNSOED) Purwokerto, 24 Januari 2010. Pendidikan Inklusif Dan Implementasinya Di Indonesia, Hal: 2.

Lópe, Ag. F. (2016). Social Skills Training for Autistic Children: A Comparison Study Between Inclusion and Mainstreaming Education. Academic Journal of Pediatrics \& Neonatology, 1(3), 65-74.

Mambela, S. (2010). Mainstreaming sebagai Alternatif Penanganan Pendidikan Anak Berkebutuhan Khusus di Indonesia. Sosiohumanika, 3(2), 295-304.

Nazir, M. (2003). Metode Penelitian. Jakarta: Ghalia Indonesia.

Pramartha, I. N. B. (2015). Sejarah Dan Sistem Pendidikan Sekolah Luar Biasa Bagian a Negeri Denpasar Bali. Historia, 3(2), 67.

Rahim, A. (2016). Pendidikan Inklusif Sebagai Strategi Dalam Mewujudkan Pendidikan Untuk Semua. Jurnal Pendidikan Ke-SD-An, 3, 68-71.

Stubbs, S. (2008). Inclusive Education Where there are few resources. In I. Lewis (Ed.), North.

Shofa, M. F. (2018). Implementasi Manajemen Pendidikan Inklusi di PAUD Inklusi Saymara Kartasura. At-Tarbawi: Jurnal Kajian Kependidikan Islam, 3(2). 